\title{
National spectral data and learning algorithms for potentially toxic elements modelling in forest soil horizons
}

Asa Gholizadeh ${ }^{\mathrm{a}}$, Mohammadmehdi Saberioon ${ }^{\mathrm{b}}$, Eyal Ben-Dor ${ }^{\mathrm{c}}$, Raphael A. Viscarra Rossel ${ }^{\mathrm{d}}$, Lubos Boruvka ${ }^{\mathrm{a}}$

${ }^{a}$ Department of Soil Science and Soil Protection, Faculty of Agrobiology, Food and Natural Resources, Czech University of Life Sciences Prague, Kamycka 129, Suchdol, Prague 16500, Czech Republic

${ }^{b}$ Helmholtz Centre Potsdam GFZ German Research Centre for Geosciences, Section 1.4 Remote Sensing and Geoinformatics, Telegrafenberg, Potsdam 14473, Germany ${ }^{c}$ Remote Sensing Laboratory, Department of Geography and Human Environment, Porter School of Environment and Earth Science, Tel Aviv University, Tel Aviv 69978, Israel ${ }^{d}$ Soil and Landscape Science, School of Molecular and Life Sciences, Faculty of Science and Engineering, Bentley Campus, Curtin University, G.P.O. Box U1987, Perth WA 6845, Australia

\section{Abstract}

Forest ecosystems are among the main parts of the biosphere; however, they have been endangered from the significant elevation and harmful effects of air and soil pollutants, including potentially toxic elements (PTEs). The concentration of PTEs in forest soils varies not only laterally but also vertically with depth. Forest surface organic horizons are of particular interest in forest ecosystem monitoring due to their role as stable adsorbents of the deposited atmospheric substances. Therefore, the main purpose of this study was to conduct rapid examinations of forest soils PTEs $(\mathrm{Cr}, \mathrm{Cu}, \mathrm{Pb}, \mathrm{Zn}$, and $\mathrm{Al}$ ), testing the capability of VIS-NIR spectroscopy coupled with machine learn-

*Email address: gholizadeh@af.czu.cz (Asa Gholizadeh)

**Email address: saberioon@gfz-potsdam.de (Mohammadmehdi Saberioon) 
ing (ML) techniques (partial least square regression (PLSR), support vector machine regression (SVMR), and random forest (RF)) and fully connected neural network (FNN), a deep learning (DL) approach, in forest organic horizons. One-thousand-and-eighty forested sites across the Czech Republic at two soil layers, defining the fragmented (F) and humus $(\mathrm{H})$ organic horizons, were investigated (total 2160 samples). PTEs as well as total Fe and SOC, as auxiliary data, were conventionally and spectrally determined and modelled in the combined organic horizons $(\mathrm{F}+\mathrm{H})$ and in each individual horizon using the ML and DL algorithms. Results indicated that the concentration of all PTEs was higher in the horizon $\mathrm{H}$ compared to the F horizon. Although the spectral reflectance of samples tended to decrease with increased PTEs concentration. Strongly significant positive correlations between all PTEs and total $\mathrm{Fe}$ in all horizons were obtained, which were higher in the $\mathrm{H}$ and $\mathrm{F}+\mathrm{H}$ horizons than the F horizon. The highest correlations of PTEs with the spectra were at $460-590 \mathrm{~nm}$, which is mostly linked to the presence of Fe-oxide. These results show the importance of Fe for spectral prediction of PTEs. $\mathrm{Cr}$ and $\mathrm{Al}$ were the most accurately predicted elements, regardless of the applied learning technique. SVMR provided the best results in assessing the $\mathrm{H}$ horizon (e.g., $\mathrm{R}^{2}=0.88$ and root mean square error (RMSE) $=3.01 \mathrm{mg} / \mathrm{kg}$, and $\mathrm{R}^{2}=0.82$ and $\mathrm{RMSE}=1682.25 \mathrm{mg} / \mathrm{kg}$ for $\mathrm{Cr}$ and $\mathrm{Al}$, respectively); however, FNN predicted the combined $\mathrm{F}+\mathrm{H}$ horizons the best $\left(\mathrm{R}^{2}=0.89\right.$ and $\mathrm{RMSE}=2.95 \mathrm{mg} / \mathrm{kg}$, and $\mathrm{R}^{2}=0.86$ and $\mathrm{RMSE}=$ $1593.64 \mathrm{mg} / \mathrm{kg}$ for $\mathrm{Cr}$ and $\mathrm{Al}$, respectively) due to the larger number of samples. In the F horizon, almost no parameters were predicted adequately. This study shows that given the availability of a larger sample size, FNN can be 
a more promising technique compared to ML methods for assessment of $\mathrm{Cr}$ and $\mathrm{Al}$ concentration based on national spectral data in the forests of the Czech Republic.

Keywords: Soil contamination, Organic horizon, Reflectance spectroscopy, Machine learning, Deep learning.

\section{Introduction}

2

Soil is considered the most dynamic, complex, and biodiverse habitat that exists, providing many benefits for humans (Wall et al., 2015). It provides fundamental natural resources for the survival of most terrestrial life (Du \& Zhou, 2011) and, as an open system exchanges matter and energy with its surrounding atmosphere, lithosphere, biosphere, and hydrosphere (Shi et al., 2018). However, it is subjected to severe human disturbance by industrial activities, which represent the main global change driver (Smith et al., 2015) leading to serious soil degradation, including soil contamination (Gholizadeh \& Kopackova, 2019).

Potentially toxic elements (PTEs), as a main group of soil contaminants, can be found in soluble and adsorbed fractions. Their accumulation in soil harms the environment and endangers ecosystems and human health (Srivastava et al., 2017; Sihag et al., 2019) via energy and material cycling (Sun et al., 2009). Soil receives PTEs in various ways, including mineral dust and gas dust emissions from industrial enterprises and vehicles, liquid and solid household waste, sewage from agricultural enterprises, pesticides, and impurities of organic and mineral fertilizers (Su et al., 2014; Plyatsuk et al., 2019). PTEs also fall from the atmosphere into the soil, principally in the 
form of oxides that gradually dissolve, passing into hydroxides or carbonates or in the form of exchanged cations (Panchenko et al., 2018).

Soils of forested regions contain a large proportion of the world's carbon (C), minerals, and energy resources. They influence the composition and quality of the atmosphere and shape climate conditions on both a regional and global scale (Percy \& Ferretti, 2004; Baciak et al., 2015). Forest soil organic horizons and their individual layers (fragmented $(\mathrm{F})$ and humus $(\mathrm{H})$ ) as topsoil horizons are the most dynamic parts of the forest environment (Chodak et al., 2007; Pavlu et al., 2016), and are significantly affected by the airborne supply of PTEs (Boska et al., 2016; Tzvetkova et al., 2016) or by their uptake from deeper soil horizons (Sucharova et al., 2011). Moreover, the forest floor is well known for its ability to bind and retain PTEs (Stevenson, 1994). Metals derived from atmospheric deposition are trapped and held in forest organic horizons (Sucharova et al., 2011), especially the H horizon (Reimann \& Caritat, 2000), for a long time. Hence, assessment of PTE concentration and spatial variability in forest surface soil is of particular interest for the prediction of dynamics within a forest ecosystem and further remediation (Fujii et al., 2014; Tzvetkova et al., 2016).

Determining PTE concentration in soil requires large-scale sampling (Ren et al., 2009; Gholizadeh et al., 2015). In addition, due to the high spatial variability in forest topsoil, a large number of samples must be analyzed to characterize the soil adequately at a large scale (Chodak et al., 2004). Traditionally, the assessment of PTE concentration in soil has been carried out through conventional soil testing and long-term trials in sequential steps, with increasing complexity and cost (Hang et al., 2009; Liu et al., 2018a). 
Therefore, an efficient and rapid analytical approach to measuring and monitoring soil PTEs in the forest at a suitable spatial scale is desirable (Arellano et al., 2015). A fast, simple, and cost-effective method such as visible-near infrared (VIS-NIR) can potentially be used to detect PTEs in the organic horizons of forest soil (Chodak et al., 2007; Liu et al., 2018a).

Soil VIS-NIR spectra include weak, wide, and overlapping absorption bands with fundamentals in the mid-infrared (MIR) region (Gholizadeh et al., 2016). The hidden information, therefore, needs to be extracted from the spectra to establish a proxy approach to detect soil parameters (Viscarra Rossel \& Behrens, 2010). Machine learning (ML) techniques including partial least square regression (PLSR), support vector machine regression (SVMR), random forest (RF), artificial neural networks (ANN), and cubist have frequently been used to calibrate soil contamination prediction models (Kemper \& Sommer, 2002; Ferreira et al., 2008; Gholizadeh et al., 2015; Liu et al., 2018b). However, with the development of large soil spectral libraries, we need to seize the opportunity to utilize big data analytics to process the spectral data, which goes beyond using commercial software or packaged ML algorithms (Padarian et al., 2018).

\subsection{Deep learning $(D L)$}

Deep learning (DL), a deep architecture of ANN with the capability of processing large-scale data (LeCun et al., 2015), can be a solution for the shortage of ML methods in big data analysis. Its advantages over common ML algorithms are that it supports more sophisticated modelling and permits the easy use of large amounts of computational resources for training such models (Behrens et al., 2018). DL is a model made of multiple pro- 
cessing layers to learn data representation in big datasets (LeCun et al., 2015). It contains more layers and deeper architectures than traditional neural networks (Padarian et al., 2018) and tries to hierarchically learn in-depth features of input data with very deep neural networks (Chen et al., 2014). The network is first layer-wise initialized via unsupervised training and then tuned in a supervised manner, permits the use of raw or unprocessed data (e.g., images or spectra), and automatically discovers the required representations or predictions.

Currently, DL is widely used in image analysis including soil image recognition thanks to its ability to learn multiple (hierarchical) levels of data representation (LeCun et al., 2015; Li et al., 2018; Tziolas et al., 2020). However, it has only been used in reflectance spectroscopy of some basic soil properties (Padarian et al., 2018) and soil microplastic contamination (Ng et al., 2019). In spite of the key role of the soil organic horizon in the forest ecosystem and its active and firm binding of PTEs, the technique has not yet been used for VIS-NIR spectroscopy of soil PTEs, either directly or indirectly via their intercorrelation with spectrally active attributes such as soil organic carbon (SOC) and iron (Fe). VIS-NIR spectroscopy applied to high organic C soils is likely to yield different responses compared to soils with high mineral content.

One such DL model, used in this study, is fully connected neural network (FNN), which is a deep neural network architecture (Figure 1), formed by repeatedly stacking the fully connected layer and activation function after the input layer. Each node in a particular layer is connected to all nodes in the next layer. The fully connected layer provides a linear transformation and the 

Yang et al., 2019).

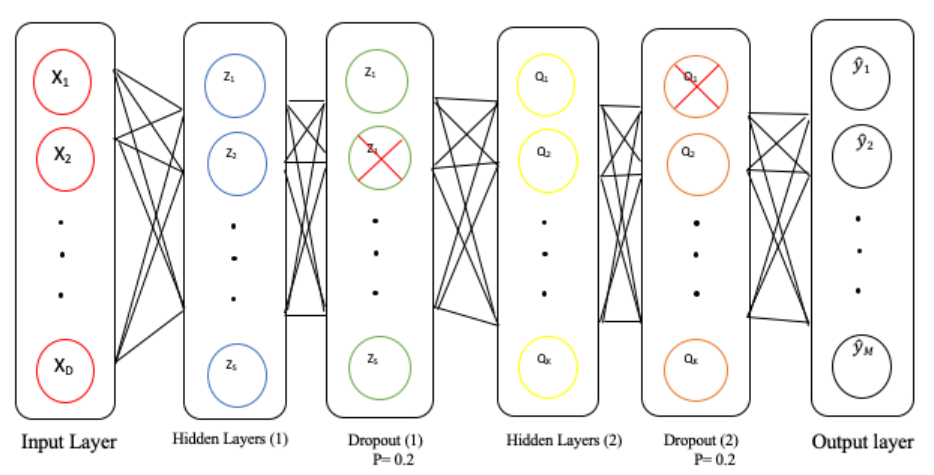

Figure 1: General structure of FNN used in this study.

activation function adds nonlinearity to extract nonlinear features from the input data. The large number of parameters in the FNN model means that it can fit arbitrary patterns theoretically, which allows new insight that can be applied to data directly. The parameters of the FNN model are optimized throughout backpropagation and the gradient descent algorithm (Qian, 1999;

(1) About one-third of the landscape of the Czech Republic is covered by forests, and over the last few decades, the country has been heavily affected by industrial activity. Consequently, this study aims to construct soil PTE $(\mathrm{Cr}, \mathrm{Cu}, \mathrm{Pb}, \mathrm{Zn}$, and $\mathrm{Al})$ prediction models through testing the capability of VIS-NIR spectroscopy coupled with DL in the organic horizon of forests of the Czech Republic. Our specific objectives are (i) to model forest soil PTEs in combined $(\mathrm{F}+\mathrm{H})$ and individual $(\mathrm{F}$ and $\mathrm{H})$ organic horizons with spectra and the DL approach (FNN), (ii) to compare the results with the results obtained from ML techniques (PLSR, SVMR, and RF), and (iii) to 
assess the predictability of the models.

\section{Materials and methods}

\subsection{Experimental sites, soil sampling, and laboratory analyses}

The total land area of the Czech Republic is $78,865 \mathrm{~km}^{2}$, of which onethird (34\%) is covered by forests (Czech Statistical Office, 2019). In this study, in order to proportionally represent various forest stands (forest composition, soil classes, and altitudes), sampling sites were distributed over all the country's forested areas. The samples originate from the Forest Soil Survey (Fiala et al., 2013) and were obtained from forested sites of the whole Czech Republic from 2000 to 2008 (Figure 2). Soil samples were collected from 1080 points separately from two individual organic horizons, $\mathrm{F}$ and $\mathrm{H}$ (total 2160 samples).

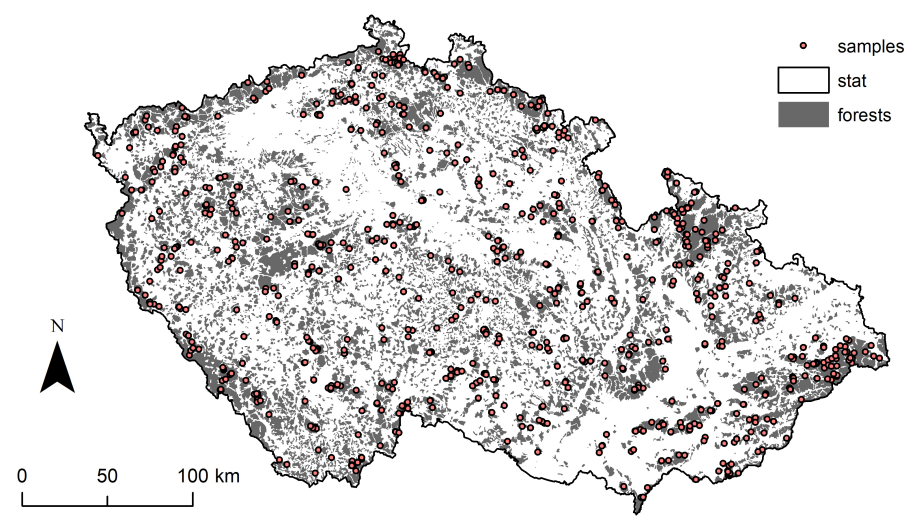

Figure 2: Location of Czech forests and soil sampling sites.

${ }_{22}$ The soil samples were air-dried, ground, sieved ( $\left.\leq 2 \mathrm{~mm}\right)$, and thoroughly mixed before soil analysis. Potentially toxic elements ( $\mathrm{Cr}, \mathrm{Cu}, \mathrm{Pb}, \mathrm{Zn}$, and 
Al) were extracted using aqua regia (ISO 11466:1995), followed by atomic absorption spectroscopy to determine their pseudo-total content. Samples and standards were matrix matched and all analyses were performed in triplicate (Gholizadeh et al., 2015). SOC and total Fe were also determined as auxiliary data for further use (since they are spectrally active parameters (Gholizadeh et al., 2018a) and have strong adsorption with PTEs) by rapid dichromate oxidation (Sparks, 1996) and aqua regia (ISO 11466:1995).

More information about the proportions of various tree species, soil classes, and altitudes can be seen in Table 1. Two-thirds of the sampling locations $(65.6 \%)$ were formed by sites with prevailing coniferous trees; the most frequent species was Norway spruce (Picea abies L. Krast., 51.5\%), followed by Scots pine (Pinus sylvestris L., 13.8\%). Among sites with prevailing broadleaved trees (34.4\%), oak (Quercus sp., 17.9\%), and European beech (Fagus sulvatica L., 16.6\%) dominated. Regarding soil classes, the dominant soil class was Cambisols (70.1\%); mostly Dystric (36.7\%), Hyperdystric (28.9\%), and Eutric (22.6\%). Podzols (15.4\%) and Stagnosols (5.2\%) were also rather ample; however, other soil classes (e.g., Arenosols, Leptosols, Retisols, Luvisols, and Fluvisols) were less frequent. Table 1 also indicates that most of the sampling sites (47.1\%) were located between $400 \mathrm{~m}$ and $600 \mathrm{~m}$ a.s.l., with fewer sites outside this range. 


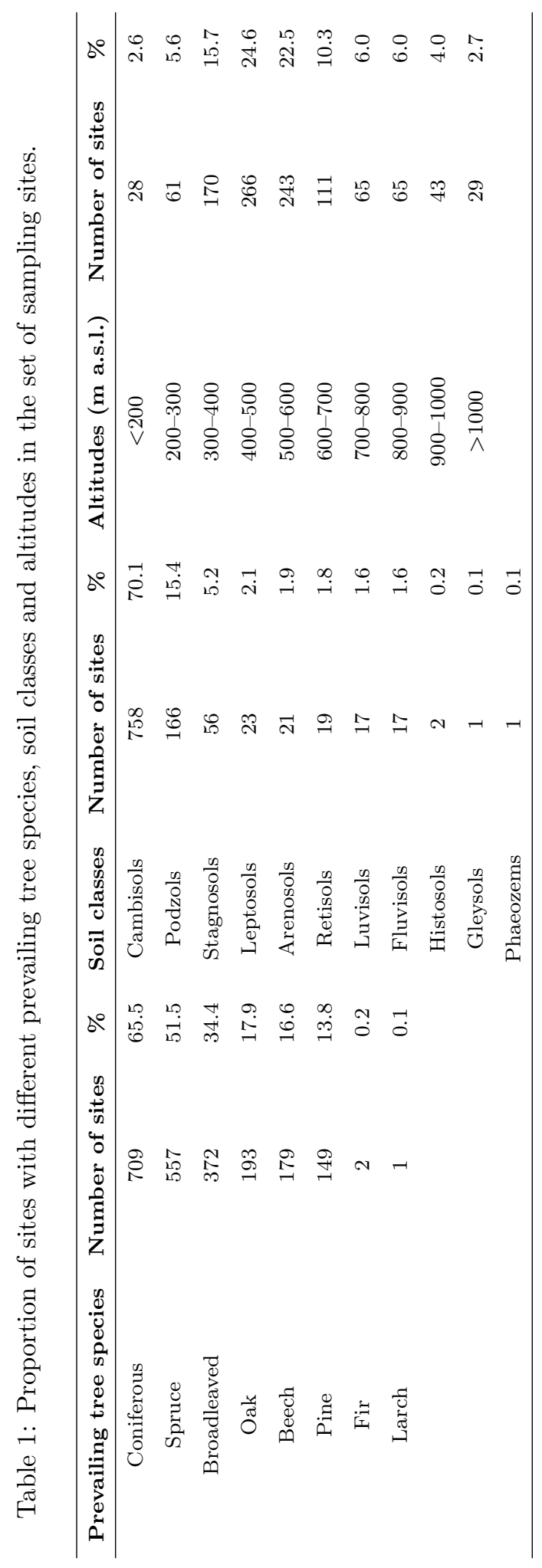




\subsection{Spectroscopic measurements and preprocessing}

Diffuse reflectance spectra were measured using an ASD FieldSpec Pro FR VIS-NIR spectrometer (ASD Inc., Denver, CO, USA) using a high-intensity contact probe in the spectral range of $350-2500 \mathrm{~nm}$. The samples were placed in $9 \mathrm{~cm}$ diameter petri dishes and formed $2 \mathrm{~cm}$ layers of soil and were scanned in the center (3 replications each) in a dark room. A Spectralon ${ }^{T M}$ (Labsphere, North Sutton, NH, USA) was used for white referencing before the first scan and once every 6 measurements (Shi et al., 2016). For each soil measurement, 30 spectra were averaged to improve the signal-to-noise ratio (SNR).

Noisy portions between $350 \mathrm{~nm}$ and $400 \mathrm{~nm}$ as well as $2451 \mathrm{~nm}$ and $2500 \mathrm{~nm}$ were removed, leaving spectra in the range from 400-2450 $\mathrm{nm}$ for further processing. The resulting spectra were then smoothed using the Savitzky-Golay approach with a second-order polynomial fit, a window size of 11 wavelengths in order to remove the artificial noise within the working spectral range (Savitzky \& Golay, 1964), and first derivatives were used to remove baseline offset (Gholizadeh et al., 2018c). In this study, in order to recognize influential outliers in a set of predictor variables, ensemble sparse partial least squares was applied (Aggarwal, 2013).

\subsection{Machine learning spectral modelling}

Each horizon's data were divided into a training (75\%) and a testing $(25 \%)$ set using random stratified sampling (Gholizadeh et al., 2018c). The training set was used to develop the regression model and the test set to validate the developed model's generalization capability (Kooistra et al., 2003). Spectral modelling of the selected soil attributes was performed using three 
ML techniques: PLSR, SVMR, and RF. The authors have previously described the implementation of techniques for spectroscopic modelling in detail (Gholizadeh et al., 2016, 2018b). All spectroscopic models were validated using 10-repeated 10-fold cross-validation (Hastie et al., 2009; Viscarra Rossel et al., 2019) and the validation statistics reported are the means of the 10 repeats.

\subsection{FNN spectral modelling}

In this experiment, the number of features of the input data was used as the number of input layer nodes. In addition to the input layer, two hidden layers, composed of neurons and rectified linear unit (leaky-ReLU) as the activation function (Zhang et al., 2017), were utilized for each soil attribute. The output layer had only one node. Additionally, Dropout regularization was employed, which randomly selects some neurons of the network and ignores them during training, while the other neurons can step in and handle the representation required to predict missing neurons. Dropout forces the network to be less sensitive to the specific weight of neurons. According to Ahmed et al. (2019), Dropout has promising generalization and using it, the network is less likely to become overfitted.

The network was trained with a batch size (i.e., a smaller sample dataset from the whole training set) of 20. The maximum number of epochs (i.e., one cycle through the entire training dataset) of the network was set at 400 . The network was trained with early stopping on the validation set with patience of 25 epochs. The model was then trained with the Adam optimizer with an initial learning rate of 0.001 to solve the optimization problem for minimizing the mean square error (MSE) function. 


\subsection{Assessment of techniques}

The final accuracy prediction was determined using standard model evaluation statistics: coefficient of determination $\left(\mathrm{R}^{2}\right)$ and the root mean squared error (RMSE). $\mathrm{R}^{2}$ is the proportion of variation in the response and is described by the regression model, and the RMSE defines the prediction ability of a model and the ME or bias is the error of means (Bellon-Maurel et al., 2010; Gomez et al., 2016).

\section{Results}

\subsection{Statistical summary and PTEs, SOC, and total Fe}

General statistical results of soil PTEs, SOC, and total Fe including mean, median, minimum (Min), maximum (Max), standard deviation (SD), coefficient of variation $(\mathrm{CV})$, and skewness from all sampling locations for the $\mathrm{F}$ $+\mathrm{H}, \mathrm{F}$, and $\mathrm{H}$ horizons are shown in Table 2. 
Table 2: Statistics description of soil attributes for each horizon.

\begin{tabular}{|c|c|c|c|c|c|c|c|}
\hline & $\mathrm{Cr}$ & $\mathrm{Cu}$ & $\mathbf{P b}$ & $\mathbf{Z n}$ & Al & $\mathbf{F e}$ & SOC \\
\hline & & & & $(\mathrm{mg} / \mathrm{kg})$ & & & $(\%)$ \\
\hline \multicolumn{8}{|c|}{ Horizons $F+H(n=2160)$} \\
\hline Mean & 20.65 & 20.96 & 98.96 & 135.98 & 6096.28 & 8671.02 & 33.68 \\
\hline Median & 17.10 & 18.25 & 85.75 & 111 & 5048.50 & 6640 & 34.83 \\
\hline Min & 3.20 & 4.79 & 14.40 & 27.20 & 315 & 527 & 11.79 \\
\hline Max & 121 & 160 & 531 & 515 & 29300 & 92000 & 48.79 \\
\hline $\mathrm{SD}$ & 13.55 & 11.47 & 57.59 & 80.26 & 4602.94 & 7618.19 & 7.35 \\
\hline $\mathrm{CV}(\%)$ & 66 & 55 & 58 & 59 & 76 & 88 & 22 \\
\hline Skewness & 1.83 & 3.44 & 2.16 & 1.10 & 1.66 & 3.77 & -0.29 \\
\hline \multicolumn{8}{|c|}{ Horizon F $(n=1080)$} \\
\hline Mean & 14.16 & 18.10 & 71.11 & 95.11 & 3659.46 & 5132.69 & 38.61 \\
\hline Median & 11.30 & 16.60 & 65.80 & 81.20 & 2820 & 4000 & 39 \\
\hline Min & 3.20 & 6.18 & 14.40 & 27.20 & 315 & 527 & 11.79 \\
\hline Max & 78.90 & 70.40 & 225.70 & 293 & 22730 & 28510 & 48.79 \\
\hline $\mathrm{SD}$ & 9.64 & 7.51 & 31.78 & 48.79 & 2832.41 & 3996.90 & 5.36 \\
\hline $\mathrm{CV}(\%)$ & 68 & 42 & 44 & 51 & 77 & 78 & 13 \\
\hline Skewness & 2.36 & 1.76 & 1.31 & 1.44 & 2.30 & 2.61 & -1.53 \\
\hline \multicolumn{8}{|c|}{ Horizon H $(n=1080)$} \\
\hline Mean & 27.15 & 23.83 & 126.14 & 176.86 & 8533.11 & 12209.35 & 28.75 \\
\hline Median & 25.4 & 21 & 118 & 177 & 7600 & 10600 & 28.48 \\
\hline Min & 6.15 & 4.79 & 27.30 & 31.40 & 1100 & 1720 & 14.60 \\
\hline Max & 121 & 160 & 531 & 515 & 29300 & 92000 & 45.98 \\
\hline $\mathrm{SD}$ & 13.78 & 13.79 & 64.40 & 84.65 & 4742.34 & 8666.60 & 5.54 \\
\hline $\mathrm{CV}(\%)$ & 51 & 58 & 51 & 48 & 56 & 71 & 19 \\
\hline Skewness & 1.95 & 3.22 & 1.98 & 0.63 & 1.55 & 3.90 & 0.18 \\
\hline
\end{tabular}

There were large variations in soil PTE content in forest soil of the F + $\mathrm{H}, \mathrm{F}$, and $\mathrm{H}$ horizons that reflect the different depths from which the samples originate. According to the pollution level defined in Czech soil quality and pollutant control standards (ČSN EN ISO 11267, 2014), Boruvka et al. (2015) and Pavlu et al. (2016), the F horizon is very close to threshold values, and the $\mathrm{H}$ horizon is classified as polluted. The average PTE content in the $\mathrm{H}$ 
horizon was very high compared with the $\mathrm{F}$ and $\mathrm{F}+\mathrm{H}$ horizons, presenting high mean values. For instance, on average, there was more than twice as much soluble $\mathrm{Al}$ in the $\mathrm{H}$ horizon (mean $=8533.11 \mathrm{mg} / \mathrm{kg}$ ) compared to the $\mathrm{F}$ horizon $($ mean $=3659.46 \mathrm{mg} / \mathrm{kg}$ ). The data distribution features were found in the $\mathrm{SD}$ values, which were higher in the $\mathrm{H}$ and $\mathrm{F}+\mathrm{H}$ horizons than the F horizon. The data for PTEs of all horizons had strong positively skewed distribution, with the highest skewness of 3.44 for $\mathrm{Cu}$ in the $\mathrm{F}+\mathrm{H}$ horizon and the lowest skewness of 0.63 for $\mathrm{Zn}$ in the $\mathrm{H}$ horizon. Table 2 also shows that the PTE content varied widely, presenting large CV values ( $\geq 55 \%, 42 \%$, and $48 \%$ in the $\mathrm{F}+\mathrm{H}, \mathrm{F}$, and $\mathrm{H}$ horizons, respectively), considered as high variability according to Wilding (1985), who categorized the datasets with $\mathrm{CV}>35 \%, 15 \%<\mathrm{CV}<35 \%$, and $\mathrm{CV}<15 \%$ as high, moderate, and low variability, respectively. In general, soluble $\mathrm{Al}$ was the most heterogeneous PTE in Czech forest soils. The total Fe statistics corresponded with the outputs obtained from PTEs, providing the highest mean of $12209.35 \mathrm{mg} / \mathrm{kg}$ and the strongest skewness of 3.90 in the $\mathrm{H}$ horizon. In terms of SOC, the $\mathrm{F}$ horizon indicated higher average than the $\mathrm{H}$ and $\mathrm{F}+\mathrm{H}$ horizons with $38.61 \% \pm 5.36 \%(\mathrm{SD})$, distribution showing low variability $(\mathrm{CV}=13 \%)$, and a negatively skewed distribution (skewness $<-1$ ).

\subsection{Horizons spectral data patterns}

Figure 3 highlights the average reflectance of the whole dataset per soil horizon with their variance. Visual inspection of the spectra shows that the overall reflectance patterns and waveforms of the spectral curves of different horizons were roughly the same; that is, the waveforms shaped an upward parabolic shape with two distinct absorption features around wavelengths 


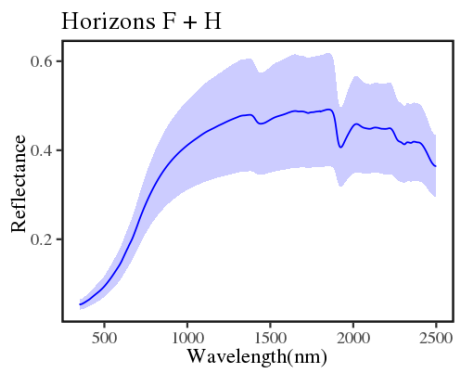

$1400 \mathrm{~nm}$ and $1900 \mathrm{~nm}$ originated by the hygroscopic moisture. Some weak features can also be seen between $2000 \mathrm{~nm}$ and $2500 \mathrm{~nm}$ wavelengths. Furthermore, the reflectance spectra of the $\mathrm{H}$ horizon were lower across the entire spectra. On this basis, the $\mathrm{F}$ horizon had higher reflectance values compared to the $\mathrm{H}$ and $\mathrm{F}+\mathrm{H}$ horizons. Overall, the spectral reflectance tended to decrease with increased PTE content (Figure 3).

Figure 3: Representative VIS-NIR average spectra (bold line) and their variance (shaded area) of soil samples collected from different horizons.
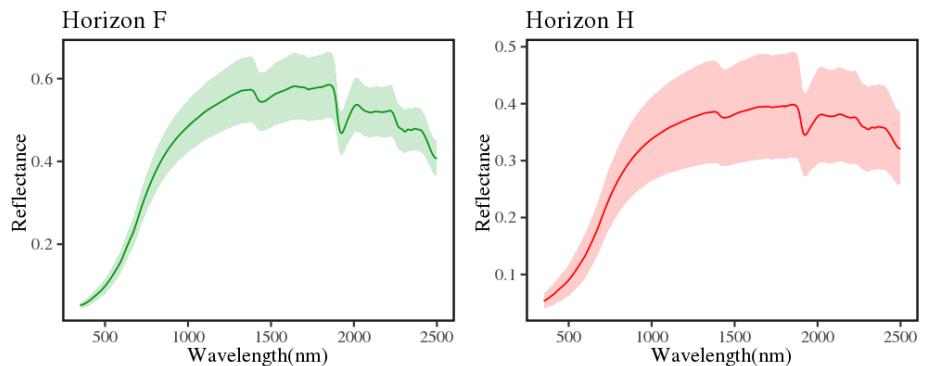

\subsection{Correlation among PTEs, SOC, and total Fe}

Correlation matrices were constructed to find the correlating soil attributes for the $\mathrm{F}+\mathrm{H}, \mathrm{F}$, and $\mathrm{H}$ horizons (Figure 4). Strong positive significant correlations among all PTEs in all horizons are obvious at $p<0.001$, implying their robust mutual dependence, although the correlations were higher for the $\mathrm{H}$ and $\mathrm{F}+\mathrm{H}$ horizons than the $\mathrm{F}$ horizon. In all horizons, the highest correlation among contaminants was observed between $\mathrm{Cr}$ and other PTEs. In contrast, the least correlation with others was with $\mathrm{Pb}(r$ $\leq 0.42$ ) in the $\mathrm{F}$ horizon. As highlighted in Figure 4, Fe was significantly and positively correlated with all PTEs $(r \geq 0.53$ in the $\mathrm{F}$ and $r \geq 0.77$ in 


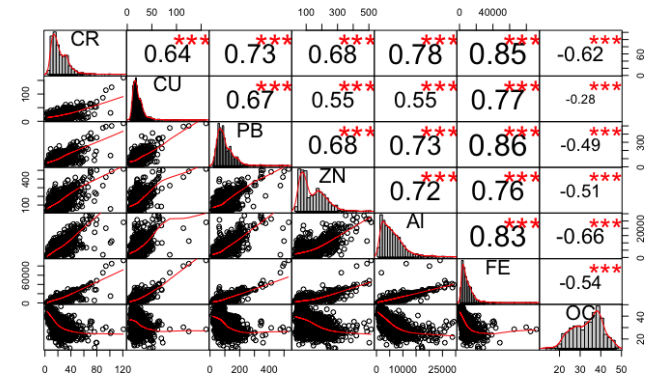

(A) at $p<0.05$.

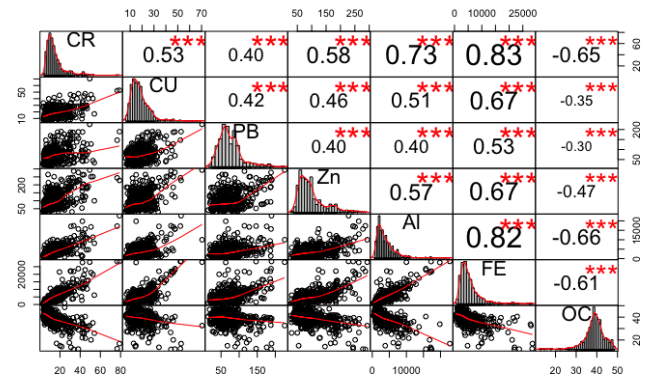

(B)

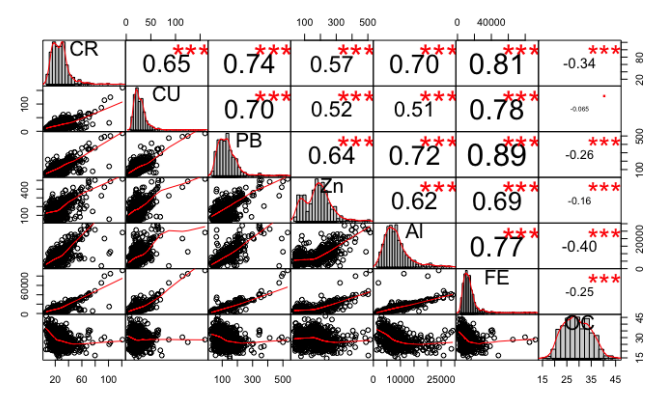

(C)

Figure 4: Correlation matrix among soil attributes at the horizons $\mathrm{F}+\mathrm{H}(\mathrm{A})$, horizon $\mathrm{F}$ (B), and horizon $\mathrm{H}(\mathrm{C}) .{ }^{* * *} p<0.001,{ }^{* *} p<0.01$, and ${ }^{*} p<0.05$

the $\mathrm{H}$ and $\mathrm{F}+\mathrm{H}$ horizons, $p<0.001)$. SOC demonstrated a moderate negative correlation with all attributes; the correlations were still significant $(p$ $<0.001$ ), and only in the $\mathrm{H}$ horizon the correlation with $\mathrm{Cu}$ was significant 

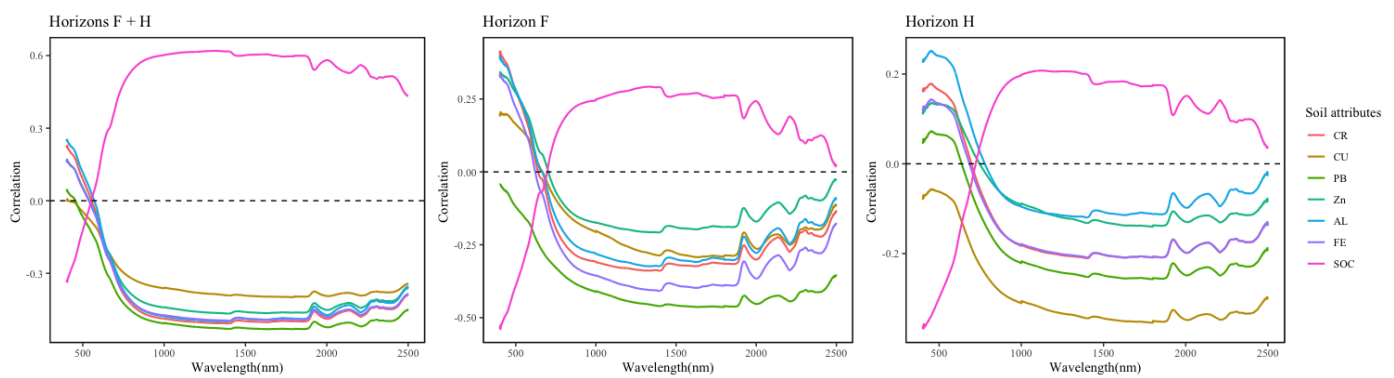

Figure 5: Correlation between soil attributes and raw spectra reflectance at different horizons.

The plots indicate that PTEs contribute to the reflectance of almost all wavelengths in the VIS-NIR range; the concentration of PTEs in the F and F $+\mathrm{H}$ horizons showed correlations in a wider range $(-0.5<r<0.4)$ throughout the studied spectral region, as they were correlated via their high content of organic matter. Figure 5 also illustrates that all toxic elements in all horizons displayed their maximum correlations in the VIS range around 430-450 $\mathrm{nm}$ and their highest negative correlations in NIR range between around $1400 \mathrm{~nm}$ and $2300 \mathrm{~nm}$. Moreover, correlation analysis indicated that the correlation coefficients of $\mathrm{Cu}$ and $\mathrm{Pb}$ were usually separated from the other PTEs. In spite of other elements correlating positively with VIS wavelengths, $\mathrm{Cu}$ and $\mathrm{Pb}$ in the $\mathrm{F}+\mathrm{H}$ horizons, $\mathrm{Pb}$ in the $\mathrm{F}$ horizon, and $\mathrm{Cu}$ in the $\mathrm{H}$ horizon had negative correlations across the VIS reflectance of soil spectra. The correlation coefficient of all PTEs with NIR reflectance spectra, in contrast to VIS spectra, fell totally into the negative section of the correlation plots, displaying relatively moderate negative spectral correlations. In general, $\mathrm{Cr}$ and $\mathrm{Al}$ had the strongest positive correlation coefficients with VIS-NIR spectra than other elements. 
According to Figure 5, the correlation of Fe in all soil horizons was in accordance with other PTEs across the entire VIS-NIR spectra (positive correlations with VIS and negative correlations with NIR wavelengths). Furthermore, Fe and Cr had very similar correlation coefficient values, particularly in the $\mathrm{H}$ horizon. Correlation changes (both pattern and value) for SOC were different from all other attributes and followed an opposite trend (Figure 5), negatively falling into the VIS range, but positive in the NIR region. In comparison with the examined PTEs, the correlation coefficients of SOC with VIS-NIR reflectance spectra in the $\mathrm{F}+\mathrm{H}$ horizons were considerably higher, with the highest $(r=0.6)$ at around $750 \mathrm{~nm}$.

\subsection{Performance of prediction models derived from techniques}

The performance of the selected ML techniques (PLSR, SVMR, and RF) and the DL approach (FNN) to extract soil PTEs, SOC, and total Fe calibration models from the spectra of forest soils can be seen in Table 3 .

Regarding PTE prediction models and the PLSR calibration set, $\mathrm{R}^{2}$ values ranged between 0.37 (for $\mathrm{Zn}$ ) and 0.82 (for $\mathrm{Cr}$ ). The best predictive models were obtained for $\mathrm{Cr}\left(\mathrm{R}^{2}=0.82\right.$ and $\left.\mathrm{RMSE}=3.16 \mathrm{mg} / \mathrm{kg}\right)$, followed by $\mathrm{Al}\left(\mathrm{R}^{2}=0.75\right.$ and $\left.\mathrm{RMSE}=2121.86 \mathrm{mg} / \mathrm{kg}\right)$. Using the SVMR technique, again $\mathrm{Cr}$ and $\mathrm{Al}$ were the most accurately predicted PTEs, with $\mathrm{R}^{2}$ value of 0.88 and 0.82 , and RMSE of $3.01 \mathrm{mg} / \mathrm{kg}$ and $1682.25 \mathrm{mg} / \mathrm{kg}$, respectively; Zn with $\mathrm{R}^{2}=0.40$ and $\mathrm{RMSE}=33.60 \mathrm{mg} / \mathrm{kg}$, was not predicted adequately. Likewise, the RF analysis of PTEs for Cr and Al showed the largest $\mathrm{R}^{2}(0.83$ and 0.78 , respectively) and lowest RMSE $(3.08 \mathrm{mg} / \mathrm{kg}$ and $2038.11 \mathrm{mg} / \mathrm{kg}$, respectively), although $\mathrm{Zn}$ again was not assessed satisfactorily. It can be seen that among all applied techniques, SVMR had the best performance, 
with the highest $\mathrm{R}^{2}$ and smallest error values for almost all PTEs assessed, followed by RF. PLSR showed the lowest $\mathrm{R}^{2}$ and largest RMSE values for all parameters; however, it still achieved fair to good prediction of $\mathrm{Cr}$ and $\mathrm{Al}$ in the Czech forested sites. Using the FNN technique, $\mathrm{Cr}$ and $\mathrm{Al}$ were the best assessed elements again, with even higher $R^{2}$ and RMSE values $\left(R^{2}=0.89\right.$, $\mathrm{RMSE}=2.95 \mathrm{mg} / \mathrm{kg}$, and $\mathrm{R}^{2}=0.86, \mathrm{RMSE}=1593.64 \mathrm{mg} / \mathrm{kg}$ ) compared to ML algorithms.

The three ML modelling strategies considered in this study displayed different prediction accuracy of the studied horizons (Table 3). Among the explored horizons, the best predictions were found in the $\mathrm{H}$ horizon, except for $\mathrm{Pb}$ and $\mathrm{Zn}$, which were better assessed in the $\mathrm{F}+\mathrm{H}$ horizon. In the $\mathrm{F}$ horizon, inadequate models (low $\mathrm{R}^{2}$ and high RMSE) were obtained for all applied techniques and all PTEs, except for Al prediction. Overall, these outcomes suggest the use of SVMR and the $\mathrm{H}$ of the horizon of Czech forest soils for fair $\left(0.50<\mathrm{R}^{2}<0.80\right)$ to good $\left(\mathrm{R}^{2}>0.81\right)$ prediction of PTEs (Chang et al., 2001). Regarding FNN, the best results for all elements were obtained in the $\mathrm{F}+\mathrm{H}$ horizon. These results were higher than the outputs of all ML methods, indicating the superiority of DL for assessing PTEs in the combined $\mathrm{F}+\mathrm{H}$ horizon with larger sample size over individual $\mathrm{F}$ and $\mathrm{H}$ layers. For the $\mathrm{F}$ and $\mathrm{H}$ horizons, FNN-derived models provided lower accuracy than SVMR and RF; however, they were still more accurate than PLSR.

As observed in Table 3, using all techniques (ML and DL), the calibration results for SOC and total Fe performed the best in the $\mathrm{F}+\mathrm{H}$ horizon using FNN, with $\mathrm{R}^{2}=0.95$ and 0.81 , and RMSE $=1.00 \mathrm{mg} / \mathrm{kg}$ and $1415.10 \mathrm{mg} / \mathrm{kg}$, 
329 respectively, indicating excellent models (Chang et al., 2001), followed by 330 SVMR, producing outcomes with the highest prediction accuracy in the F + 331 H horizon. 


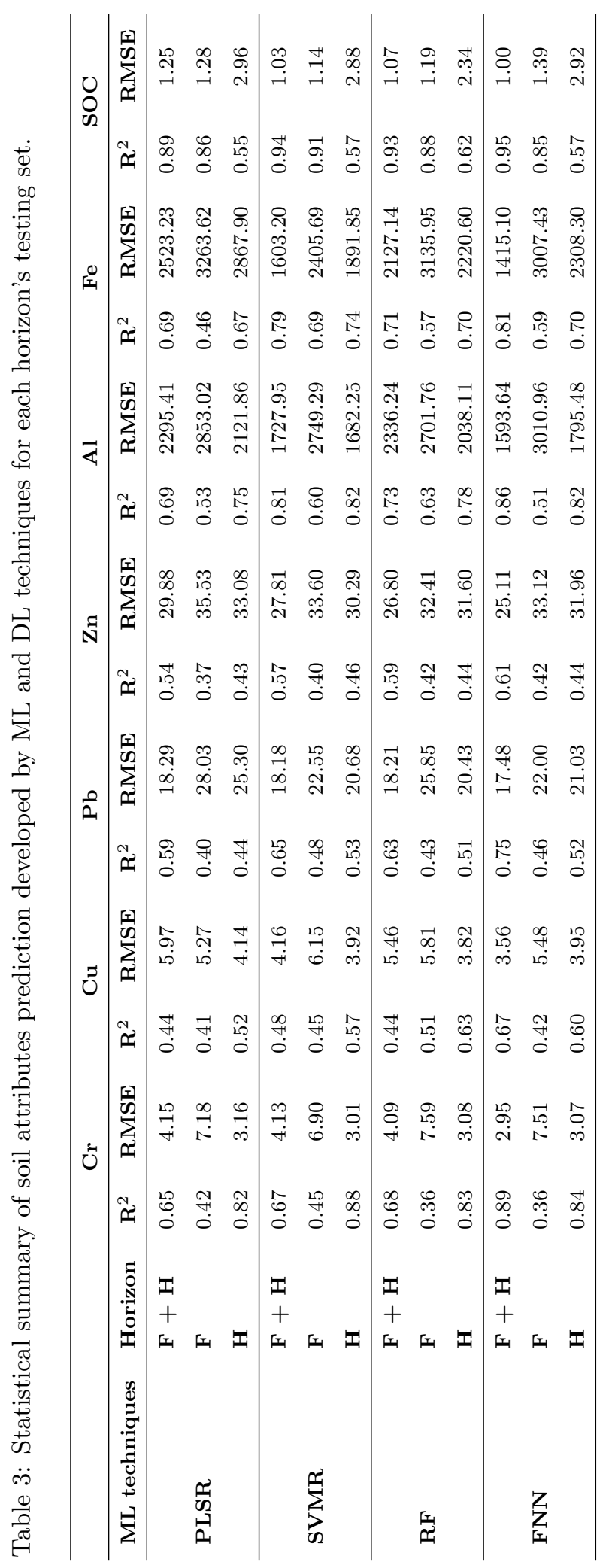




\section{Discussion}

Although Pavlu et al. (2016) found that $\mathrm{Cu}$ and Zn contents in Czech forest soils were higher in the F horizon, the soil analysis of the current study revealed that all examined PTEs were concentrated more in the $\mathrm{H}$ horizon, which is in agreement with the studies of Suchara \& Sucharov (2002) and Sucharova et al. (2011). For instance, the estimated mean concentrations of $\mathrm{Cr}$ and $\mathrm{Al}$ in the $\mathrm{H}$ horizon $(27.15 \mathrm{mg} / \mathrm{kg}$ and $8533.11 \mathrm{mg} / \mathrm{kg}$, respectively) were almost 2 times higher than those of the F horizon (Table 2). The initial vertical migration of soil contaminants from upper to lower organic layers is driven by washout and leaching (Fujii et al., 2014); however, the mobility of PTEs in soil depends on their nature, either in particle or soluble/mobile form; the mobile form attains the highest concentration in the $\mathrm{H}$ horizon (Pavlu et al., 2016). The mobility and depth distribution of PTEs in forest soil horizons are also regulated by factors such as water content, $\mathrm{pH}$, temperature, soil particle size, clay, total Fe, and Fe-oxide content (Rafferty et al., 2000; Wu et al., 2007; Xie et al., 2012; Fujii et al., 2014). The bioavailability of PTEs in soils besides other factors is mostly associated with accumulation and decomposition of SOC (Alloway, 2013). Shand et al. (1994) mentioned that higher SOC can retain higher amounts of contamination due to sorption onto clay minerals, though it can cause a reduction in PTE bioavailability by changing them from bioavailable form (Walker et al., 2004). This also reflects the accumulation of SOC with bonded elements in horizons with high C content, as documented by Pavlu et al. (2016). In this study, the mean SOC content in the $\mathrm{F}$ horizon $(38.61 \%)$ showed high $\mathrm{C}$ storage in forest soils of the Czech Republic, decreasing by depth in the H horizon (28.75\%). 
Therefore, we expected to observe a higher concentration of PTEs in the F horizon than the H horizon; however, it was the opposite (Table 2). Suchara \& Sucharov (2002) explained that because of the significantly higher decomposition and density of organic $\mathrm{C}$ in the $\mathrm{H}$ horizon of forest soil, the cation binding capacity of this layer is very high, reaching $550 \mathrm{meq} / 100 \mathrm{~g}$ of the humus substrate, and PTEs are easily bound to numerous free functional groups of humus macromolecules. The $\mathrm{H}$ horizon thus keeps a much higher concentration of PTEs than the F layer, which is mostly accumulated plant residuals. Moreover, plants take up elements via their roots from the deeper mineral soil horizons and then use leaf fall to dispose of undesired elements, including PTEs. After decomposing litter, the released PTEs are absorbed by humic substances in the $\mathrm{H}$ horizon due to the strong binding capacity of humus (Reimann \& Caritat, 2000). As such, the $\mathrm{H}$ horizon can be viewed as the "memory" of the contamination history (e.g., by PTEs) of an area (Sucharova et al., 2011).

Figure 3 shows that the spectra of all horizons had a similar typical form, with the waveforms displaying an upward parabolic shape in the VIS-NIR range (400-1000 nm) representing Fe-oxide and C concentration and type (Sherman \& Waite, 1985; Song et al., 2012). In the range of $400 \mathrm{~nm}$ to $1000 \mathrm{~nm}$, the spectral pattern of the $\mathrm{F}$ horizon (also $\mathrm{F}+\mathrm{H}$ ), containing less decomposed organic matter (e.g., leaves, needles, and little branches), can also be related to remaining photosynthetic pigments (e.g., chlorophyll, carotenoids, and xanthophylls) and vegetative cell structure (Gitelson et al., 2002). These findings were similar to the results of Ogen et al. (2017), who used the VIS-NIR range for soil classification and concluded that accumu- 
lated roots and other plant residuals on upper soil layers affected the soil spectral pattern. In the NIR range, at wavelengths $1400 \mathrm{~nm}$ and $1900 \mathrm{~nm}$, there were sharp absorption bands. There were also some weak features between $2000 \mathrm{~nm}$ and $2500 \mathrm{~nm}$ that resulted from overtones and combined vibrations of the organic functional groups methyl, methylene and aryl, carbonyl, ester and carboxyl $\mathrm{C}=\mathrm{O}$, cellulose $\mathrm{C}-\mathrm{C} / \mathrm{C}-\mathrm{H}, \mathrm{C}-\mathrm{H}$, and $\mathrm{O}-\mathrm{H}$ groups (Ben-Dor \& Banin, 1995; Viscarra Rossel \& Hicks, 2015). The NIR spectra of forest organic horizons also consist of numerous overlapping peaks related to different chemical structures (Ludwig \& Khanna, 2001). Therefore, it is impossible to exactly relate absorption at particular wavelengths to unique chemical compounds or groups of compounds (Chodak et al., 2007). In this study, as the content of PTE, total Fe, and SOC varied with depth, corresponding changes in the forest soil spectral intensities were seen. Chakraborty et al. (2015), Douglas et al. (2018), and Hong et al. (2019a) reported similar patterns and demonstrated that soil samples with higher PTE content showed lower spectral reflectance than soil samples with lower contamination levels, particularly in the spectral range of 700-2500 nm. It has also been proved that soil reflectance is decreased throughout the VIS-NIR region with increasing organic matter content (Kooistra et al., 2003). Nevertheless, as the soil horizon color varies due to PTE concentration (Douglas et al., 2018; Hong et al., 2019a), soil organic matter content (Ben-Dor et al., 2008), and structure (Zanella et al., 2017), it can influence soil spectra too (Gholizadeh et al., 2020). Therefore, in the $\mathrm{H}$ horizon, with darker color and fine and welldecomposed structure (Zanella et al., 2017), the reflectance absorbs more light energy, then the spectral curve decreases. Though intense bands in the 
VIS-NIR spectra are not directly associated with the presence of PTEs, it is clear that PTEs can bond and interact with the main spectrally active components of soil such as SOC and different forms of Fe (Wu et al., 2005; Song et al., 2012).

Based on Figure 4, the relationships of total Fe and SOC with PTE exhibited different rates, which reflect different metal dependency in different circumstances and horizons (Xie et al., 2012). The significant correlations between total Fe and PTE for the datasets were moderate to high $(0.53 \leq$ $r \leq 0.89)$, increasing by depth. SOC also displayed significant correlations with all PTEs, with higher values in the F horizon. This difference between horizons can be explained by the higher content of total Fe and SOC in the $\mathrm{H}$ and $\mathrm{F}$ horizons, respectively (Table 2), and their capability of metalsorption (Wu et al., 2005). These findings reveal that these two soil properties cannot be neglected during the PTE modelling process. In general, total Fe showed higher correlations with the studied PTEs than SOC, showing in this study that PTEs were more closely bound to Fe. Therefore, Fe significantly influenced the estimation of PTE concentration from the reflectance spectra of the forest soil samples. Thus, in the VIS-NIR spectral estimation of PTEs in Czech forested sites, total Fe had higher priority to interact with the five PTEs than with SOC. These results were similar to the results of Kemper \& Sommer (2002) in estimating $\mathrm{Pb}$, as well as the results of Khosravi et al. (2017) and Khosravi et al. (2018) in estimating As, Pb, and Zn. In contrast, Chen et al. (2014) and Hong et al. (2019b) showed a higher correlation of SOC with $\mathrm{Zn}$ and $\mathrm{Pb}$ compared to Fe forms. The differences in these mechanisms may be caused by different soil-forming environments and land-use types in 
various areas (Hong et al., 2019a).

In order to confirm our findings, the correlation coefficients between VISNIR reflectance and PTEs across the spectral range (Figure 5) were assessed, which represent the primary mechanism of estimating toxic elements by spectroscopy (Rathod et al., 2015; Khosravi et al., 2018). IIt can be seen that the concentrations of toxic elements and total Fe in all horizons followed the same pattern, with similar peaks and valleys, in their correlations with the VISNIR reflectance of soil spectra. The highest positive correlations of PTEs were in the VIS region (at about 460-590 nm), which are mainly attributed to the presence of Fe-oxide (Ben-Dor, 2002; Xie et al., 2012; Gholizadeh et al., 2018a). Similar results were also reported by Wu et al. (2005) and Wu et al. (2007) regarding the substantial role of Fe in the spectral relation of PTEs. These findings emphasize the importance of $\mathrm{Fe}$ in the spectral estimation of PTEs in this study area, especially in the $\mathrm{H}$ and $\mathrm{F}+\mathrm{H}$ horizons with high concentrations of total Fe. Few SOC correlation features (specifically in the F horizon) were consistent with those of PTE. In addition, the high negative correlation of PTEs with the spectra was mainly identified at wavebands of 1380-1450 nm and 1860-2000 nm (Xie et al., 2012), which are mostly governed by the content of SOC and darkness of humic acid (Knadel et al., 2013; Shi et al., 2015). Thus, the SOC related spectral features also need to be considered in study of PTEs, suggesting that the role of SOC cannot be ignored in the spectral modelling procedure of the examined PTEs in forest soils of the Czech Republic. It should also be noted that the differences between soil horizons mirror the effects of the various soil attribute contents and metal-sorption by Fe and SOC concentration. 
The effectiveness of various ML predicting algorithms (PLSR, SVMR, and RF) and the DL technique (FNN) to extract PTE calibration models from the reflectance spectra of forest soil horizons in the VIS-NIR range was compared (Table 3). Different prediction accuracies were obtained, and their adequacy was evaluated based on maximal $\mathrm{R}^{2}$ and minimal RMSE. According to the evaluation criterion, among the studied PTEs, $\mathrm{Cr}$ and $\mathrm{Al}$ were the best predicted elements, whether they were based on ML or DL methods. This was expected based on the strong positive correlation coefficients of these elements with VIS-NIR spectra (Figure 5). This may be linked to their high concentration and their strong internal relations with spectrally active soil components (Ben-Dor, 2002; Xie et al., 2012), especially total Fe in this study (Figure 5). For $\mathrm{Zn}$ and $\mathrm{Cu}$, the $\mathrm{R}^{2}$ and RMSE values of different methods were not as good as they were for the other elements, implying that the prediction models derived from VIS-NIR spectra were not able to handle $\mathrm{Zn}$ and $\mathrm{Cu}$ in forest soils of the Czech Republic (Table 3). Chodak et al. (2007), Xie et al. (2012), and Gholizadeh et al. (2015) obtained comparable results when assessing these elements using VIS-NIR spectra using various ML methods. Chodak et al. (2007) mentioned that, since deposited PTEs can exist in an inorganic form (e.g., contained in deposited dust), they cannot be determined by VIS-NIR. Similarly, Siebielec et al. (2004) found that VIS-NIR spectroscopy underestimated the $\mathrm{Zn}$ and $\mathrm{Cu}$ contents in heavily polluted soils of Poland and ascribed the imprecise predictions of these elements to the presence of a large proportion of dustborne PTEs. Considering forest soil horizons, it can be noticed that the $\mathrm{H}$ layer with high SD of PTE concentration (Table 2) was the most accurately assessed horizon using 
ML algorithms. Kuang \& Mouazen (2011) found that variability in the concentration range of PTEs significantly affects the performance of calibration models, and a wider range and larger SD lead to higher accuracy. Of the horizons, the $\mathrm{H}$ horizon had the largest SD values, which might explain its high accuracy. Applying the FNN approach, the best prediction performance was seen for the combined horizon $(\mathrm{F}+\mathrm{H})$. Due to the nature of $\mathrm{DL}$, this can be related to the bigger sample size (LeCun et al., 2015; Padarian et al., 2018) at this merged dataset.

Compared to FNN, SVMR, and RF, PLSR showed the lowest modelling accuracy in all cases. The reason is that PLSR is a linear method and does not perform well in solving nonlinear-linear problems (Wei et al., 2019). It is also apparent in Table 3 that among ML approaches, the best predictions in nearly all cases, regardless of the soil element, were achieved by SVMR. One may justify the superior performance of SVMR by its capability to approximate nonlinear functions between multidimensional space (Bilgili et al., 2010; Gholizadeh et al., 2016). This algorithm can also derive linear hyperplanes as a decision function for nonlinear problems, which reduces problems with heterogeneity and nonlinearity and can be considered as another reason for the method's excellence (Clairotte et al., 2016). The superiority of the SVMR technique has been proved in several studies related to soil parameter prediction in general (Viscarra Rossel \& Behrens, 2010; Araujo et al., 2014; Jiang et al., 2019), and soil PTE assessment in particular (Gholizadeh et al., 2015; Khosravi et al., 2017).

Considering the FNN results in Table 3, it can be noticed that in terms of prediction capability, this DL method had the best predictability when 
the number of samples was higher $(\mathrm{F}+\mathrm{H}$ horizon), which indicates the robustness of FNN using larger sample sizes. In the individual layers (F and $\mathrm{H}$ ), the model accuracy obtained from FNN was lower than (although comparable to) predictive models of SVMR and RF but still higher than PLSR. According to Jiang et al. (2019), the reason is that the SVMR and RF methods achieve maximum reliability for the prediction of smaller samples. Generally speaking, regarding the obtained results in the Czech Republic's forested sites, the examined DL technique (FNN) was considered to be the best theory for assessing PTEs (particularly $\mathrm{Cr}$ and $\mathrm{Al}$ ) based on national spectral data when a large number of samples is accessible. However, if a small sample size is involved, it is better to couple SVMR with spectral data for modelling of PTEs. Nevertheless, future studies should still focus on better exploring the effects of different soil sample sizes, especially higher numbers of samples, on the performance of ML and DL calibration models using spectral data. Additionally, other DL architectures and algorithms need to be investigated to obtain better prediction accuracy.

\section{Conclusions}

This study explored the potential of the combined use of soil VIS-NIR spectroscopy and learning algorithms (ML and DL) in organic horizons of thee Czech Republic's forested sites to model soil PTEs (Cr, Cu, Pb, Zn, and $\mathrm{Al}$ ). PTE content was higher in the $\mathrm{H}$ horizon and the reflectance spectra decreased with increased soil PTE concentration. The darker color and welldecomposed structure of the $\mathrm{H}$ horizon and its capability of metal-sorption caused the absorbance of more light energy and the decline of the spectral 
curve. PTEs showed the highest positive correlation with VIS-NIR spectra in the VIS region (at about $460-590 \mathrm{~nm}$ ). The highest correlation among the studied parameters was observed between PTEs and total Fe content. These results highlight the importance of Fe in the spectral prediction of PTEs in this study area, particularly in the $\mathrm{H}$ and $\mathrm{F}+\mathrm{H}$ horizons with higher total Fe content compared to the F layer. Among all PTEs, $\mathrm{Cr}$ and $\mathrm{Al}$ were the most accurately predicted elements regardless of the applied learning technique, and the successful mechanism of their estimation by using reflectance spectroscopy was mainly described by their high correlation and close relationship with SOC and especially Fe as soil spectrally active attributes. Using the ML methods and a smaller sample size $(\mathrm{n}=1080)$, SVMR and the $\mathrm{H}$ layer were the best algorithm and horizon for predicting PTEs $\left(\mathrm{R}^{2}=\right.$ 0.88 and $\mathrm{RMSE}=3.01 \mathrm{mg} / \mathrm{kg}$, and $\mathrm{R}^{2}=0.82$ and $\mathrm{RMSE}=1682.25 \mathrm{mg} / \mathrm{kg}$ for $\mathrm{Cr}$ and $\mathrm{Al}$, respectively). The FNN approach had the best performance in predicting PTEs (mainly $\mathrm{Cr}$ and $\mathrm{Al}: \mathrm{R}^{2}=0.89$ and $\mathrm{RMSE}=2.95 \mathrm{mg} / \mathrm{kg}$, and $\mathrm{R}^{2}=0.86$ and $\mathrm{RMSE}=1593.64 \mathrm{mg} / \mathrm{kg}$, respectively) in the combined $\mathrm{F}+\mathrm{H}$ horizon due to the larger sample size $(\mathrm{n}=2160)$, which is a prerequisite for training in DL. In the $\mathrm{F}$ horizon, inadequate models (low $\mathrm{R}^{2}$ and high RMSE) were obtained using all techniques. All in all, the proposed FNN model in this paper coupled with spectral data indicate the feasibility of modeling PTEs ( $\mathrm{Cr}$ and $\mathrm{Al}$ ) based on national spectral data in the forests of the Czech Republic. 


\section{Acknowledgement}

The authors like to thank the financial support of the Czech Science Foundation (project No. 18-28126Y). The authors also thank the Central Institute for Supervising and Testing in Agriculture for providing the samples and data. The kind efforts of Mr. Josef Kratina and Mr. Karel Nemecek for soil spectra measurement and providing the study area detailed map are greatly appreciated.

\section{References}

Aggarwal, C. C. (2013). Outlier ensembles: position paper. ACM SIGKDD Explorations Newsletter, 14, 49. doi:10.1145/2481244.2481252.

Ahmed, A. M., Duran, O., Zweiri, Y., \& Smith, M. (2019). Quantification of Hydrocarbon Abundance in Soils Using Deep Learning with Dropout and Hyperspectral Data. Remote Sensing, 11, 1938. doi:10.3390/rs11161938.

Alloway, B. J. (2013). Sources of heavy metals and metalloids in soils. In B. J. Alloway (Ed.), Heavy Metals in Soils: Trace Metals and Metalloids in Soils and their Bioavailability (pp. 11-50). Dordrecht: Springer Netherlands. doi:10.1007/978-94-007-4470-7-2.

Araujo, S. R., Wetterlind, J., Dematt, J. A. M., \& Stenberg, B. (2014). Improving the prediction performance of a large tropical visNIR spectroscopic soil library from Brazil by clustering into smaller subsets or use of data mining calibration techniques. European Journal of Soil Science, 65, 718-729. doi:10.1111/ejss.12165. 
Arellano, P., Tansey, K., Balzter, H., \& Boyd, D. S. (2015). Detecting the effects of hydrocarbon pollution in the Amazon forest using hyperspectral satellite images. Environmental Pollution, 205, 225-239. doi:10.1016/j.envpol.2015.05.041.

Baciak, M., Warmiski, K., \& Bes, A. (2015). The effect of selected gaseous air pollutants on woody plants. Forest Research Papers, 76, 401-409. doi:10.1515/frp-2015-0039.

Behrens, T., Schmidt, K., MacMillan, R. A., \& Viscarra Rossel, R. (2018). Multi-scale digital soil mapping with deep learning. Scientific Reports, 8, 15244. doi:10.1038/s41598-018-33516-6.

Bellon-Maurel, V., Fernandez-Ahumada, E., Palagos, B., Roger, J.-M., \& McBratney, A. (2010). Critical review of chemometric indicators commonly used for assessing the quality of the prediction of soil attributes by NIR spectroscopy. TrAC Trends in Analytical Chemistry, 29, 1073-1081. doi:10.1016/j.trac.2010.05.006.

Ben-Dor, E. (2002). Quantitative remote sensing of soil properties. In Advances in Agronomy (pp. 173 - 243). Academic Press volume 75. doi:10.1016/S0065-2113(02)75005-0.

Ben-Dor, E., \& Banin, A. (1995). Near-Infrared Analysis as a Rapid Method to Simultaneously Evaluate Several Soil Properties. Soil Science Society of America Journal, 59. doi:10.2136/sssaj1995.03615995005900020014x.

Ben-Dor, E., Heller, D., \& Chudnovsky, A. (2008). A Novel Method of 
Classifying Soil Profiles in the Field using Optical Means. Soil Science Society of America Journal, 72, 1113. doi:10.2136/sssaj2006.0059.

Bilgili, A. V., Es, H. v., Akbas, F., Durak, A., \& Hively, W. (2010). Visiblenear infrared reflectance spectroscopy for assessment of soil properties in a semi-arid area of Turkey. Journal of Arid Environments, 74, 229-238. doi:10.1016/j.jaridenv.2009.08.011.

Boruvka, L., Sramek, V., Cupr, P., Fadrhonsova, V., Hofman, J., Houska, J., Sanka, O., Slavikova, A. A., Sindelarova, L., Tejnecky, V., Vasckova, J., Sanka, M., Cechmankova, J., Drabek, O., Frankova, A., Horvathova, V., Rotter, P., Skala, J., Novotny, R., Shudoma, M., Vacha, R., \& Jurkovska, L. (2015). Srovnávací hodnoty pro hodnocen kontaminace lesnch pud: certifikovaná metodika. -. Strnady: Výzkumný ústav lesnho hospodářství a myslivosti. Strnady: Vzkumn stav lesnho hospodstv a myslivosti.

Boska, E., Lasota, J., Szuszkiewicz, M., ukasik, A., \& Klamerus-Iwan, A. (2016). Assessment of forest soil contamination in Krakow surroundings in relation to the type of stand. Environmental Earth Sciences, 75, 1205. doi:10.1007/s12665-016-6005-7.

Chakraborty, S., Weindorf, D. C., Li, B., Aldabaa], A. A. A., Ghosh, R. K., Paul, S., \& Ali], M. N. (2015). Development of a hybrid proximal sensing method for rapid identification of petroleum contaminated soils. Science of The Total Environment, 514, 399 - 408. doi:10.1016/j.scitotenv.2015.01.087.

Chang, C.-W., Laird, D. A., Mausbach, M. J., \& Hurburgh, C. R. (2001). 
Near-Infrared Reflectance Spectroscopy-Principal Components Regression Analyses of Soil Properties. Soil Science Society of America Journal, 65, 480-490. doi:10.2136/sssaj2001.652480x.

Chen, Y., Lin, Z., Zhao, X., Wang, G., \& Gu, Y. (2014). Deep LearningBased Classification of Hyperspectral Data. IEEE Journal of Selected Topics in Applied Earth Observations and Remote Sensing, 7, 2094-2107. doi:10.1109/jstars.2014.2329330.

Chodak, M., Khanna, P., Horvath, B., \& Beese, F. (2004). Near Infrared Spectroscopy for Determination of Total and Exchangeable Cations in Geologically Heterogeneous Forest Soils. Journal of Near Infrared Spectroscopy, 12, 315-324. doi:10.1255/jnirs.440.

Chodak, M., Nikliska, M., \& Beese, F. (2007). Near-infrared spectroscopy for analysis of chemical and microbiological properties of forest soil organic horizons in a heavy-metal-polluted area. Biology and Fertility of Soils, 44 , 171-180. doi:10.1007/s00374-007-0192-z.

Clairotte, M., Grinand, C., Kouakoua, E., Thbault, A., Saby, N. P., Bernoux, M., \& Barths, B. G. (2016). National calibration of soil organic carbon concentration using diffuse infrared reflectance spectroscopy. Geoderma, 276, 41-52. doi:10.1016/j.geoderma.2016.04.021.

ČSN EN ISO 11267 (2014). Kvalita pudy - Inhibice reprodukce chvostoskoku (Folsomia candida) látkami znečištujícími pudu.

Czech Statistical Office (2019). Surveying, mapping and cadastre. URL: https://vdb.czso.cz. 
Douglas, R., Nawar, S., Alamar, M., Mouazen, A., \& Coulon, F. (2018). Rapid prediction of total petroleum hydrocarbons concentration in contaminated soil using vis-nir spectroscopy and regression techniques. Science of The Total Environment, 616-617, 147 - 155. doi:10.1016/j.scitotenv.2017.10.323.

Du, C., \& Zhou, J. (2011). Application of Infrared Photoacoustic Spectroscopy in Soil Analysis. Applied Spectroscopy Reviews, 46, 405-422. doi:10.1080/05704928.2011.570837.

Ferreira, E. C., Milori, D. M. B. P., Ferreira, E. J., Silva, R. M. D., \& Martin-Neto, L. (2008). Artificial neural network for Cu quantitative determination in soil using a portable Laser Induced Breakdown Spectroscopy system. Spectrochimica Acta Part B: Atomic Spectroscopy, 63, 1216-1220. doi:10.1016/j.sab.2008.08.016.

Fiala, P., Reininger, D., Samek, T., Nemec, P., \& Susil, A. (2013). Pruzkum vyzivy lesa na uzemi Ceske Republiky 19962011. Technical Report Central Institute for Supervising and Testing in Agriculture.

Fujii, K., Ikeda, S., Akama, A., Komatsu, M., Takahashi, M., \& Kaneko, S. (2014). Vertical migration of radiocesium and clay mineral composition in five forest soils contaminated by the Fukushima nuclear accident. Soil Science and Plant Nutrition, 60, 751-764. doi:10.1080/00380768.2014.926781.

Gholizadeh, A., Boruvka, L., Saberioon, M., \& Vasat, R. (2016). A MemoryBased Learning Approach as Compared to Other Data Mining Algorithms 
for the Prediction of Soil Texture Using Diffuse Reflectance Spectra. Remote sensing, 8. doi:10.3390/rs8040341.

Gholizadeh, A., Boruvka, L., Vat, R., Saberioon, M., Klement, A., Kratina, J., Tejnecky, V., \& Drabek, O. (2015). Estimation of Potentially Toxic Elements Contamination in Anthropogenic Soils on a Brown Coal Mining Dumpsite by Reflectance Spectroscopy: A Case Study. PLoS ONE, 10. doi:10.1371/journal.pone.0117457.

Gholizadeh, A., \& Kopackova, V. (2019). Detecting vegetation stress as a soil contamination proxy: a review of optical proximal and remote sensing techniques. International Journal of Environmental Science and Technology, 16, 2511-2524. doi:10.1007/s13762-019-02310-w.

Gholizadeh, A., Saberioon, M., Ben-Dor, E., \& Borvka, L. (2018a). Monitoring of selected soil contaminants using proximal and remote sensing techniques: Background, state-of-the-art and future perspectives. Critical Reviews in Environmental Science and Technology, (pp. 1-36). doi:10.1080/10643389.2018.1447717.

Gholizadeh, A., Saberioon, M., Carmon, N., Boruvka, L., \& Ben-Dor, E. (2018b). Examining the Performance of PARACUDA-II Data-Mining Engine versus Selected Techniques to Model Soil Carbon from Reflectance Spectra. Remote Sensing, 10, 1172. doi:10.3390/rs10081172.

Gholizadeh, A., Saberioon, M., Viscarra Rossel, R., Boruvka, L., \& Klement, A. (2020). Spectroscopic measurements and imaging of soil colour 
for field scale estimation of soil organic carbon. Geoderma, 35\%, 113972. doi:10.1016/j.geoderma.2019.113972.

Gholizadeh, A., ZiZala, D., Saberioon, M., \& Borvka, L. (2018c). Soil organic carbon and texture retrieving and mapping using proximal, airborne and Sentinel-2 spectral imaging. Remote Sensing of Environment, 218, 89-103. doi:10.1016/j.rse.2018.09.015.

Gitelson, A. A., Zur, Y., Chivkunova, O. B., \& Merzlyak, M. N. (2002). Assessing Carotenoid Content in Plant Leaves with Reflectance Spectroscopy. Photochemistry and Photobiology, 75, 272-281. doi:10.1562/0031-8655(2002)0750272ACCIPL2.0.CO2.

Gomez, C., Gholizadeh, A., Borvka, L., \& Lagacherie, P. (2016). Using legacy data for correction of soil surface clay content predicted from VNIR/SWIR hyperspectral airborne images. Geoderma, 276, 84-92. doi:10.1016/j.geoderma.2016.04.019.

Hang, X., Wang, H., Zhou, J., Ma, C., Du, C., \& Chen, X. (2009). Risk assessment of potentially toxic element pollution in soils and rice (Oryza sativa) in a typical area of the Yangtze River Delta. Environmental Pollution, 157, 2542-2549. doi:10.1016/j.envpol.2009.03.002.

Hastie, T., Tibshirani, R., \& Friedman, J. (2009). The Elements of Statistical Learning: Data Mining, Inference and Prediction. New York, NY, USA: Springer.

Hong, Y., Shen, R., Cheng, H., Chen, S., Chen, Y., Guo, L., He, J., Liu, Y., Yu, L., \& Liu, Y. (2019a). Cadmium concentration estimation in 
peri-urban agricultural soils: Using reflectance spectroscopy, soil auxiliary information, or a combination of both? Geoderma, 354, 113875. doi:10.1016/j.geoderma.2019.07.033.

Hong, Y., Shen, R., Cheng, H., Chen, Y., Zhang, Y., Liu, Y., Zhou, M., Yu, L., Liu, Y., \& Liu, Y. (2019b). Estimating lead and zinc concentrations in peri-urban agricultural soils through reflectance spectroscopy: Effects of fractional-order derivative and random forest. Science of The Total Environment, 651, 1969 - 1982. doi:https://doi.org/10.1016/j.scitotenv.2018.09.391.

ISO 11466:1995 (1995). Soil Quality Extraction of Trace Elements Soluble in Aqua Regia. Standard International Organization for Standardization Geneva, $\mathrm{CH}$.

Jiang, H., Rusuli, Y., Amuti, T., \& He, Q. (2019). Quantitative assessment of soil salinity using multi-source remote sensing data based on the support vector machine and artificial neural network. International Journal of Remote Sensing, 40 , 284-306. doi:10.1080/01431161.2018.1513180.

Kemper, T., \& Sommer, S. (2002). Estimate of Heavy Metal Contamination in Soils after a Mining Accident Using Reflectance Spectroscopy. Environmental Science $\& 3$ Technology, 36, 2742-2747. doi:10.1021/es015747j.

Khosravi, V., Ardejani, F. D., \& Yousefi, S. (2017). Spectroscopic-based assessment of the content and geochemical behaviour of arsenic in a highly heterogeneous sulphide-rich mine waste dump. Environmental Earth Sciences, 76, 459. doi:10.1007/s12665-017-6793-4. 
Khosravi, V., Ardejani, F. D., Yousefi, S., \& Aryafar, A. (2018). Monitoring soil lead and zinc contents via combination of spectroscopy with extreme learning machine and other data mining methods. Geoderma, 318, 29-41. doi:10.1016/j.geoderma.2017.12.025.

Knadel, M., Viscarra Rossel, R., Deng, F., Thomsen, A., \& Greve, M. H. (2013). VisibleNear Infrared Spectra as a Proxy for Topsoil Texture and Glacial Boundaries. Soil Science Society of America Journal, 77, 568-579. doi:10.2136/sssaj2012.0093.

Kooistra, L., Wanders, J., Epema, G., Leuven, R., Wehrens, R., \& Buydens, L. (2003). The potential of field spectroscopy for the assessment of sediment properties in river floodplains. Analytica Chimica Acta, 484, 189-200. doi:10.1016/s0003-2670(03)00331-3.

Kuang, B., \& Mouazen, A. (2011). Calibration of visible and near infrared spectroscopy for soil analysis at the field scale on three European farms. European Journal of Soil Science, 62, 629-636. doi:10.1111/j.13652389.2011.01358.x.

LeCun, Y., Bengio, Y., \& Hinton, G. (2015). Deep learning. Nature, 521, 436. doi:10.1038/nature14539.

Li, J., Xi, B., Li, Y., Du, Q., \& Wang, K. (2018). Hyperspectral Classification Based on Texture Feature Enhancement and Deep Belief Networks. Remote Sensing, 10, 396. doi:10.3390/rs10030396.

Liu, M., Wang, T., Skidmore, A. K., \& Liu, X. (2018a). Heavy metalinduced stress in rice crops detected using multi-temporal Sentinel- 
2 satellite images. Science of The Total Environment, 637, 18-29. doi:10.1016/j.scitotenv.2018.04.415.

Liu, X., Liu, F., Huang, W., Peng, J., Shen, T., \& He, Y. (2018b). Quantitative Determination of $\mathrm{Cd}$ in Soil Using Laser-Induced Breakdown Spectroscopy in Air and Ar Conditions. Molecules, 23, 2492. doi:10.3390/molecules23102492.

Ludwig, B., \& Khanna, P. (2001). Use of near infrared spectroscopy to determine inorganic and organic carbon fractions in soil and litter. In R. Lal, J. Kimble, R. Follett, \& B. Stewart (Eds.), Assessment methods for soil carbon. (pp. 361-370). CRC/Lewis Publishers.

Ng, W., Minasny, B., \& McBratney, A. (2019). Convolutional Neural Network for soil microplastic contamination screening using infrared spectroscopy. Science of The Total Environment, (p. 134723). doi:10.1016/j.scitotenv.2019.134723.

Ogen, Y., Goldshleger, N., \& Ben-Dor, E. (2017). 3D spectral analysis in the VNIRSWIR spectral region as a tool for soil classification. Geoderma, 302, 100-110. doi:10.1016/j.geoderma.2017.04.020.

Padarian, J., Minasny, B., \& McBratney, A. (2018). Using deep learning to predict soil properties from regional spectral data. Geoderma Regional, 16, e00198. doi:10.1016/j.geodrs.2018.e00198.

Panchenko, T., Pradivlyana, A., \& Ursul, O. (2018). Estimation of the influence of thermal energy objects on the environment. In Materialy 
XLVII Naukovo-Tekhnichnoyi Konferentsiyi Pidrozdiliv VNTU, Vinnytsya (p. 4574). URL: https://conferences.vntu.edu.ua/index.php/ all-fksa/all-fksa-2018/paper/view/4574.

Pavlu, L., Drbek, O., Borvka, L., Nikodem, A., \& Nmeek, K. (2016). Degradation of forest soils in the vicinity of an industrial zone. Soil and Water Research, 10, 65-73. doi:10.17221/220/2014-swr.

Percy, K. E., \& Ferretti, M. (2004). Air pollution and forest health: toward new monitoring concepts. Environmental Pollution, 130, 113-126. doi:10.1016/j.envpol.2003.10.034.

Plyatsuk, L. D., Chernysh, Y. Y., Ablieieva, I. Y., Yakhnenko, O. M., Bataltsev, E. V., Balintova, M., \& Hurets, L. L. (2019). Remediation of Soil Contaminated with Heavy Metals. Journal of Engineering Sciences, 6, h1-h8. doi:10.21272/jes.2019.6(1).h1.

Qian, N. (1999). On the momentum term in gradient descent learning algorithms. Neural Networks, 12, 145 - 151. doi:10.1016/S0893-6080(98)001166.

Rafferty, B., Brennan, M., Dawson, D., \& Dowding, D. (2000). Mechanisms of $137 \mathrm{Cs}$ migration in coniferous forest soils. Journal of Environmental Radioactivity, 48, 131-143. doi:10.1016/s0265-931x(99)00027-2.

Rathod, P. H., Mller, I., Meer, F. D. V. d., \& Smeth, B. d. (2015). Analysis of visible and near infrared spectral reflectance for assessing metals in soil. Environmental monitoring and assessment, 188, 558. doi:10.1007/s10661016-5568-9. 
Reimann, C., \& Caritat, P. d. (2000). Intrinsic Flaws of Element Enrichment Factors (EFs) in Environmental Geochemistry. Environmental Science 86 Technology, 34, 5084-5091. doi:10.1021/es001339o.

Ren, H.-Y., Zhuang, D.-F., Singh, A., Pan, J.-J., Qiu, D.-S., \& Shi, R.H. (2009). Estimation of As and Cu Contamination in Agricultural Soils Around a Mining Area by Reflectance Spectroscopy: A Case Study. Pedosphere, 19. doi:10.1016/S1002-0160(09)60167-3.

Savitzky, A., \& Golay, M. (1964). Smoothing and Differentiation of Data by Simplified Least Squares Procedures. Analytical Chemistry, 36 . doi:10.1021/ac60214a047.

Shand, C. A., Cheshire, M. V., Smith, S., Vidal, M., \& Rauret, G. (1994). Distribution of radiocaesium in organic soils. Journal of Environmental Radioactivity, 23, 285-302. doi:10.1016/0265-931x(94)90067-1.

Sherman, D. M., \& Waite, T. D. (1985). Electronic spectra of fe3+ oxides and oxyhydroxides in the near infrared to ultraviolet. American Mineralogist, 70, 1262-1269.

Shi, T., Guo, L., Chen, Y., Wang, W., Shi, Z., Li, Q., \& Wu, G. (2018). Proximal and remote sensing techniques for mapping of soil contamination with heavy metals. Applied Spectroscopy Reviews, 53, 1-23. doi:10.1080/05704928.2018.1442346.

Shi, T., Wang, J., Chen, Y., \& Wu, G. (2016). Improving the prediction of arsenic contents in agricultural soils by combining the reflectance spec- 
troscopy of soils and rice plants. International Journal of Applied Earth Observation and Geoinformation, 52, 95-103. doi:10.1016/j.jag.2016.06.002.

Shi, Z., Ji, W., Viscarra Rossel, R. A., Chen, S., \& Zhou, Y. (2015). Prediction of soil organic matter using a spatially constrained local partial least squares regression and the chinese visnir spectral library. European Journal of Soil Science, 66, 679-687. doi:10.1111/ejss.12272.

Siebielec, G., McCarty, G. W., Stuczynski, T. I., \& Reeves, J. B. (2004). Near- and Mid-Infrared Diffuse Reflectance Spectroscopy for Measuring Soil Metal Content. Journal of Environmental Quality, 33, 2056-2069. doi:10.2134/jeq2004.2056.

Sihag, P., Keshavarzi, A., \& Kumar, V. (2019). Comparison of different approaches for modeling of heavy metal estimations. SN Applied Sciences, 1, 780. doi:10.1007/s42452-019-0816-6.

Smith, P., House, J. I., Bustamante, M., Sobock, J., Harper, R., Pan, G., West, P. C., Clark, J. M., Adhya, T., Rumpel, C., Paustian, K., Kuikman, P., Cotrufo, M. F., Elliott, J. A., McDowell, R., Griffiths, R. I., Asakawa, S., Bondeau, A., Jain, A. K., Meersmans, J., \& Pugh, T. A. M. (2015). Global change pressures on soils from land use and management. Global change biology, 22, 1008-28. doi:10.1111/gcb.13068.

Song, Y., Li, F., Yang, Z., Ayoko, G. A., Frost, R. L., \& Ji, J. (2012). Diffuse reflectance spectroscopy for monitoring potentially toxic elements in the agricultural soils of Changjiang River Delta, China. Applied Clay Science, 64, 75-83. doi:10.1016/j.clay.2011.09.010. 
Sparks, D. (1996). Methods of Soil Analysis. Part 3 Chemical Methods.. Madison, WI, USA: Soil Science Society of America, American Society of Agronomy.

Srivastava, V., Sarkar, A., Singh, S., Singh, P., Araujo, A. S. F. d., \& Singh, R. P. (2017). Agroecological Responses of Heavy Metal Pollution with Special Emphasis on Soil Health and Plant Performances. Frontiers in Environmental Science, 5, 64. doi:10.3389/fenvs.2017.00064.

Stevenson, F. (1994). Humus Chemistry. Genesis, Composition, Reactions. John Wiley \& Sons.

Su, C., Jiang, L., \& Zhang, W. (2014). A review on heavy metal contamination in the soil worldwide:Situation, impact and remediation techniques. Environmental Skeptics and Critics, 3, 24-38.

Suchara, I., \& Sucharov, J. (2002). Distribution of Sulphur and Heavy Metals in Forest Floor Humus of the Czech Republic. Water, Air, and Soil Pollution, 136, 289-316. doi:10.1023/a:1015235924991.

Sucharova, J., Suchara, I., Hola, M., Reimann, C., Boyd, R., Filzmoser, P., \& Englmaier, P. (2011). Linking chemical elements in forest floor humus (Ohhorizon) in the Czech Republic to contamination sources. Environmental Pollution, 159, 1205-1214. doi:10.1016/j.envpol.2011.01.041.

Sun, Y., Zhou, Q., Xie, X., \& Liu, R. (2009). Spatial, sources and risk assessment of heavy metal contamination of urban soils in typical regions of Shenyang, China. Journal of hazardous materials, 174, 455-62. doi:10.1016/j.jhazmat.2009.09.074. 
Tziolas, N., Tsakiridis, N., Ben-Dor, E., Theocharis, J., \& Zalidis, G. (2020). Employing a multi-input deep convolutional neural network to derive soil clay content from a synergy of multi-temporal optical and radar imagery data. Remote sensing, 12. doi:10.3390/rs12091389.

Tzvetkova, N., Malinova, L., Doncheva, M., Bezlova, D., Petkova, K., Karatoteva, D., \& Venkova, R. (2016). Soil contamination in forest and industrial regions of bulgaria. In Soil Contamination - Current Consequences and Further Solutions. doi:10.5772/64716.

Viscarra Rossel, R., \& Behrens, T. (2010). Using data mining to model and interpret soil diffuse reflectance spectra. Geoderma, 158. doi:10.1016/j.geoderma.2009.12.025.

Viscarra Rossel, R., \& Hicks, W. S. (2015). Soil organic carbon and its fractions estimated by visiblenear infrared transfer functions. European Journal of Soil Science, 66, 438-450. doi:10.1111/ejss.12237.

Viscarra Rossel, R., Lee, J., Behrens, T., Luo, Z., Baldock, J., \& Richards, A. (2019). Continental-scale soil carbon composition and vulnerability modulated by regional environmental controls. Nature Geoscience, 12, 547-552. doi:10.1038/s41561-019-0373-z.

Walker, D. J., Clemente, R., \& Bernal, M. P. (2004). Contrasting effects of manure and compost on soil $\mathrm{pH}$, heavy metal availability and growth of Chenopodium album L. in a soil contaminated by pyritic mine waste. Chemosphere, 57, 215-224. doi:10.1016/j.chemosphere.2004.05.020. 
Wall, D. H., Nielsen, U. N., \& Six, J. (2015). Soil biodiversity and human health. Nature, 528, 69-76. doi:10.1038/nature15744.

Wei, L., Yuan, Z., Yu, M., Huang, C., \& Cao, L. (2019). Estimation of Arsenic Content in Soil Based on Laboratory and Field Reflectance Spectroscopy. Sensors, 19, 3904. doi:10.3390/s19183904.

Wilding, L. (1985). Spatial variability: its documentation, accomodation and implication to soil surveys. In J. PBouma, \& D. R. Nielsen (Eds.), Workshop on Soil spatial variability.

Wu, Y., Chen, J., Ji, J., Gong, P., Liao, Q., Tian, Q., \& Ma., H. (2007). A mechanism study of reflectance spectroscopy for investigating heavy metals in soils. Soil Sci. Soc. Am. J., 71, 918-926. doi:10.2136/sssaj2006.0285.

Wu, Y., Chen, J., Wu, X., Tian, Q., Ji, J., \& Qin, Z. (2005). Possibilities of reflectance spectroscopy for the assessment of contaminant elements in suburban soils. Applied Geochemistry, 20, 1051-1059. doi:10.1016/j.apgeochem.2005.01.009.

Xie, X.-L., Pan, X.-Z., \& Sun, B. (2012). Visible and Near-Infrared Diffuse Reflectance Spectroscopy for Prediction of Soil Properties near a Copper Smelter. Pedosphere, 22. doi:10.1016/S1002-0160(12)60022-8.

Yang, J., Xu, J., Zhang, X., Wu, C., Lin, T., \& Ying, Y. (2019). Deep learning for vibrational spectral analysis: Recent progress and a practical guide. Analytica Chimica Acta, . doi:10.1016/j.aca.2019.06.012.

Zanella, A., Ponge, J.-F., Jabiol, B., Sartori, G., Kolb, E., Gobat, J.-M., Bayon, R.-C. L., Aubert, M., Waal, R. D., Delft, B. V., Vacca, A., 
Serra, G., Chersich, S., Andreetta, A., Cools, N., Englisch, M., Hager, H., Katzensteiner, K., Brthes, A., Nicola, C. D., Testi, A., Bernier, N., Graefe, U., Juilleret, J., Banas, D., Garlato, A., Obber, S., Galvan, P., Zampedri, R., Frizzera, L., Tomasi, M., Menardi, R., Fontanella, F., Filoso, C., Dibona, R., Bolzonella, C., Pizzeghello, D., Carletti, P., Langohr, R., Cattaneo, D., Nardi, S., Nicolini, G., \& Viola, F. (2017). Humusica 1, article 4: Terrestrial humus systems and formsSpecific terms and diagnostic horizons. Applied Soil Ecology, 122, 56-74. doi:10.1016/j.apsoil.2017.07.005.

Zhang, X.-Y., Bengio, Y., \& Liu, C.-L. (2017). Online and offline handwritten Chinese character recognition: A comprehensive study and new benchmark. Pattern Recognition, 61, 348-360. doi:10.1016/j.patcog.2016.08.005. 